СТАТЬИ

УДК 630.181:630.4:551.52:631.438:574.2

НОВЫЙ ПОДХОД К ЛЕСОПАТОЛОГИЧЕСКИМ ИССЛЕДОВАНИЯМ В ЗОНАХ РАДИОАКТИВНОГО ЗАГРЯЗНЕНИЯ

\author{
${ }^{1}$ Гниненко Ю.И., ${ }^{1}$ Калнин В.В., ${ }^{2}$ Кучук В.А., ${ }^{1}$ Марадудин И.И., ${ }^{1}$ Мартынюк А.А., \\ ${ }^{1}$ Радин А.И., ${ }^{1}$ Раздайводин А.Н. \\ ${ }^{1}$ ФБУ «Всероссийский НИИ лесоводства и механизации лесного хозяйства», Пушкино, \\ e-mail: info@roslesrad.ru; \\ ${ }^{2}$ Филиал ФБУ «Российский ичентр защиты леса», «Центр защиты леса Калужской области», \\ Брянск, e-mail: kychykva@rcfh.ru
}

\begin{abstract}
В статье рассматривается новый подход к изучению влияния радиоактивного загрязнения на развитие очагов вредных организмов в лесных экосистемах. Дается краткий обзор материалов по исследованиям санитарного состояния загрязненных лесов и воздействия ионизирующих излучений на вредные организмы. Предлагается использование методологического подхода оценки влияния радиоактивного загрязнения на возникновение и развитие очагов вредителей и болезней леса на основе статистического анализа больших выборок с использованием многолетних данных лесопатологических и радиационных обследований. Показано наличие влияния радиационного фактора на возникновение очагов вредных организмов. Установлено, что связь радиоактивного загрязнения с возникновением и развитием очагов может носить нелинейный и разнонаправленный характер в зависимости от вида патогена и уровней радиоактивного загрязнения. Приведены примеры влияния радиоактивного загрязнения цезием-137 чернобыльского происхождения на формирование очагов смоляного рака сосны (Peridermium pini (Willd.) Kleb.), корневой губки (Heterobasidion annosum Fr.), рыжего соснового пилильщика (Neodiprion sertifer Geoffr). Выдвинуто предположение, что радиационный фактор оказывает значимое влияние на формирование очагов вредных организмов и реализуется через комплексное воздействие, включающее прямое влияние ионизирующего излучения на организм и популяцию патогена; косвенное влияние через воздействие излучения на другие виды лесных экосистем и их связи; влияние через изменения режима хозяйственной деятельности, связанные с условиями радиоактивного загрязнения. Предложено выделить подобные исследования в новое направление радиационной экологии леса - радиационную лесопатологию.
\end{abstract}

Ключевые слова: радиоактивное загрязнение лесов, радиоэкология, радиационная лесопатология, защита леса, лесозащитные мероприятия, лесопатологический мониторинг, радиационный мониторинг лесов

\title{
NEW APPROACH TO FOREST-PATHOLOGICAL RESEARCH IN ZONES OF RADIOACTIVE CONTAMINATION
}

\author{
${ }^{1}$ Gninenko Yu.I., ${ }^{1}$ Kalnin V.V., ${ }^{2}$ Kuchuk V.A., ${ }^{1}$ Maradudin I.I., ${ }^{1}$ Martynyuk A.A., \\ ${ }^{1}$ Radin A.I., ${ }^{1}$ Razdayvodin A.N. \\ ${ }^{1}$ Russian Research Institute of Silviculture and Mechanization of Forestry, \\ Pushkino,e-mail:info@roslesrad.ru; \\ ${ }^{2}$ Branch office FBI «Russian Centre of Forest Health», «Kaluga Centre of Forest Health», \\ Bryansk,e-mail: kychykva@rcfh.ru
}

\begin{abstract}
The article considers a new approach to studying the effect of radioactive contamination upon development of source of harmful organisms in forest ecosystems. A brief review of materials on the research of the sanitary state of contaminated forests and the effects of ionizing radiation on pests is presented. It is proposed that methodological approach is used to assess the impact of radioactive contamination on the occurrence and development of sources of pests and forest diseases based upon statistical analysis of large massives of samples using long-term data of forest pathological and radiation surveys. The influence of radiation factor formation of sources of harmful organisms is shown. It has been established that the association of radioactive contamination with the occurrence and development of these sources may be non-linear and multidirectional, depending on the type of pathogen and levels of radioactive contamination. Examples of the effect of radioactive contamination with cesium-137 of Chernobyl origin on the formation of sources of resin pine cancer (Peridermium pini (Willd.) Kleb.), pine fungus (Heterobasidion annosum Fr.), red pine sawfly (Neodiprion sertifer Geoffr) are given. It is suggested that the radiation factor has a significant effect on the formation of sources of harmful organisms and is realized through a complex effect, including the direct influence of ionizing radiation upon organisms and pathogen population; indirect influence through the effect of radiation on other types of forest ecosystems and their relationships; influence through changes in the mode of economic activity associated with the conditions of radioactive contamination. It was proposed to highlight such studies in the new direction of forest radiation ecology - radiation forest pathology.
\end{abstract}

Keywords: radioactive contamination of forests, radioecology, radiation forest pathology, forest protection, forest protection measures, forest pathological monitoring, radiation monitoring of forest

Использование атомной энергии, как в военных, так и в мирных целях, привело к загрязнению окружающей среды радио- нуклидами искусственного происхождения. Основными источниками поступления радионуклидов в экосистемы послужили 
ядерные испытания и радиационные инциденты 3-7 уровней по шкале событий МАГАТЭ [1], связанные с выходом загрязнения за пределы полигонов и промышленных площадок. Наиболее крупными из них являются: взрыв в хранилище высокоактивных жидких радиоактивных отходов на ПО Маяк в 1957 г, аварии на Чернобыльской АЭС в 1986 г. и АЭС Фукусима в 2011 г.

Большинство этих аварий носили характер «сельских» [2]. Они привели к значительным загрязнениям агроценозов и лесных экосистем. По состоянию на 2019 г. к зонам радиоактивного загрязнения на территории России отнесено около 1 млн га земель лесного фонда. Основной вклад в загрязнение лесов в настоящее время вносят техногенные изотопы цезий-137 и стронций-90.

В период до чернобыльской аварии проводились лабораторные исследования по воздействию ионизирующих излучений на модельные и некоторые хозяйственно значимые виды патогенных организмов, изучались генетические и популяционные показатели, оценивались дозы подавления, стерилизации и гибели, рассматривалось применение ионизирующих излучений для контроля численности вредителей. Не проводилось комплексных исследований влияния радиоактивного загрязнения на санитарное состояние лесов и развитие очагов вредных организмов.

Наиболее интересными были работы по искусственному облучению лесных участков [3], в которых в том числе оценивалось поведение насекомых-вредителей. Однако условия эксперимента (облучение лесного участка от внешнего мощного источника) значительно отличались от последствий аварийного загрязнения (долговременное облучение от включенных в биологический круговорот и динамически перераспределяемых радионуклидов в лесах, загрязненных в результате аварий), а непосредственное примыкание к неповрежденным насаждениям вносило дополнительные погрешности в результаты.

Авария на Чернобыльской АЭС потребовала срочной разработки нормативных документов по осуществлению защитных мероприятий (контрмер), что привело к необходимости проведения прикладных исследований в полевых условиях. В период с 1986 по начало 2000-х гг. рядом исследователей (Ю.Д. Абатуров, А.М. Жуков, В.В. Жуков, Г.М. Козубов, Д.А. Криволуцкий, Н.Д. Кучма, Г.В. Линдеман, А.В. Панфилов, Е.Н. Панфилова, Ф.А. Тихомиров и др.) изучались последствия радиоактивно- го загрязнения вследствие аварии на ЧАЭС для лесных экосистем. Было оценено санитарное состояние лесов в 30-км зоне отчуждения. Исследован видовой состав дендрофильных насекомых. Установлено, что резкое ухудшение санитарного состояния в сосновых древостоях наступает при плотности радиоактивного загрязнения свыше 600 Ки/км². Выдвинуты предположения о возможном отрицательном воздействии насекомых-вредителей на процесс восстановления ослабленных ионизирующим излучением насаждений. Показано, что принципиальных изменений в видовом составе и популяционных характеристиках, однозначно связанных с радиационным фактором, в зонах загрязнения не отмечается. Установлено значимое влияние на патогенные организмы изменения режимов хозяйственной деятельности $[4,5]$.

Большинство исследований затрагивали отдельные виды или группы видов, либо санитарное состояние насаждений в зонах радиоактивного загрязнения. После выхода работы А.М. Жукова «Динамика лесопатологического состояния древостоев на загрязненных радионуклидами территориях» [5] крупных системных исследований в области защиты леса в условиях радиоактивного загрязнения не публиковалось.

\section{Материалы и методы исследования}

В литературных источниках хорошо описано явление гормезиса - стимулирующего эффекта умеренных доз стрессоров, или, по определению авторов этого термина, «стимулирующего действия субингибирующих концентраций любого токсического вещества любого организма», в том числе радиационного гормезиса при воздействии малых доз радиации [6]. Наши исследования в опытах по искусственному облучению фитопатогенных грибов показали, что может наблюдаться картина общего адаптационного синдрома (ОАС) и изменения стрессовой реакции организма (CPO) по Г. Селье [7].

Осуществляемые в соответствии с Лесным кодексом РФ лесопатологические обследования предусматривают выявление очагов вредных организмов [8,9]. В процессе основной деятельности филиалов ФБУ «Рослесозащита» накапливаются многолетние данные о выявленных очагах. Это позволило ФБУ ВНИИЛМ совместно с Центром защиты леса Калужской области объединить данные об очагах вредных организмов и радиоактивном загрязнении 
лесных участков на примере лесов Брянской области. Объем базы данных составил более 80000 записей с глубиной наблюдений более 10 лет.

Большое количество наблюдений позволяет использовать широкий диапазон статистических методов и получать высокую достоверность результатов.

\section{Результаты исследования и их обсуждение}

Для предварительного анализа массива объединенных данных лесопатологических и радиологических обследований были использованы непараметрические методы. Полученные значения рангового (непараметрического) гамма-коэффициента корреляции между плотностью радиоактивного загрязнения и повреждающими факторами для основных лесообразующих пород показали, что многие выявленные связи с большой вероятностью могут рассматриваться как реально существующие. Дальнейший анализ позволил впервые выявить достоверные связи и устойчивые тренды между возникновением очагов ряда хозяйственно значимых видов насекомых-вредителей и болезней с плотностью загрязнения почвы лесных участков цезием-137.

Были получены зависимости частоты встречаемости очагов вредных организмов (относительно общего количества обследованных участков, на которых присутствовала повреждаемая древесная порода), от плотности загрязнения почв лесных участков цезием-137. Некоторые результаты поведения вредных организмов, поражающих сосну обыкновенную (Pinus sylvestris L.), приведены далее.

Смоляной рак сосны (Peridermium pini (Willd.) Kleb.) демонстрирует устойчивую отрицательную зависимость возникновения очагов с плотностью загрязнения почвы, хорошо описываемую кривой двухкомпонентной зависимости доза - эффект (рис. $1, \mathrm{~A}$ ):

$$
\begin{gathered}
\mathrm{S}_{1}=554,31 * 0,99 /\left(1+10^{\wedge}\left(\left(-364,35-\mathrm{v}_{1}\right) *(-0,01)\right)\right), \\
\mathrm{S}_{2}=554,31 *(1-0,99) / \\
\left(1+10^{\wedge}\left(\left(751,84-\mathrm{v}_{1}\right) *(-0,09)\right)\right), \\
\mathrm{S}=8,99 \mathrm{E}+\mathrm{S}_{1}+\mathrm{S}_{2},
\end{gathered}
$$

где $\mathrm{v}_{\text {- }}$ плотность загрязнения почвы цезием-137, кБк/ м $^{2}$;

$\mathrm{S}$ - частота встречаемости очагов Peridermium pini (Willd.) Kleb. относительно к общему количеству обследованных участков, на которых присутствует повреждаемая порода.
Как видно из рис. 1, Б, полученная кривая хорошо описывает экспериментальные данные. Корреляция между ожидаемой (расчетной) и фактической вероятностью возникновения очагов очень высока - коэффициент детерминации $\mathrm{r}^{2}=0,9477$, уровень значимости $\mathrm{p}<1 * 10^{-4}$.

На графике (рис. 1, А) хорошо выделяются две ступени, при плотности загрязнения почвы около 100 кБк/м² $(2,7$ Ки/км²) и свыше

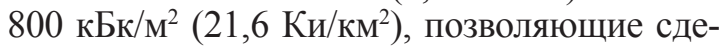
лать вывод о значимом влиянии радиационного фактора уже вблизи нижней границы официально выделяемой зоны радиоактивного загрязнения - 37 кБк/м² (1 Ки/км²).

Корневая губка на сосне демонстрирует устойчивую положительную связь возникновения очагов с плотностью радиоактивного загрязнения лесных участков (рис. 2).

Рыжий сосновый пилильщик показывает устойчивый обратный тренд. Поскольку линейный тренд не достигает порога достоверности (рис. 3), дополнительно был проведен расчет с использованием натурального логарифма почвенного загрязнения:

$$
\begin{gathered}
\mathrm{y}=0,122-0,0191 * \operatorname{Ln}(\mathrm{x}) ; \\
\mathrm{r}=-0,5821 ; \mathrm{p}=0,0089 ; \mathrm{r}^{2}=0,3389
\end{gathered}
$$

Звездчатый ткач пилильщик не выявлен в условиях радиоактивного загрязнения. Сосновая губка демонстрирует индифферентность к фактору загрязнения.

Полученные результаты согласуются с отмечаемой многими исследователями нелинейностью зависимости доза - эффект, подтвержденной нами в экспериментах по искусственному облучению семян и патогенных грибов [7]. К аналогичным выводам позволяют прийти результаты морфогенетических исследований, показавшие наибольшую чувствительность в области низких и средних уровней загрязнения [10].

Установлено наличие связей между плотностью загрязнения цезием-137 почв лесных участков и развитием патогенных организмов. Эти связи могут носить нелинейный и разнонаправленный характер в зависимости от уровня загрязнения. Анализ литературных данных, результаты наших полевых наблюдений и характер выявленных связей позволяет предположить, что радиационный фактор оказывает значимое влияние на формирование очагов вредных организмов и реализуется через комплексное воздействие, включающее:

- прямое влияние ионизирующего излучения на организм и популяцию патогена; 
- косвенное влияние через воздействие излучения на другие виды лесных экосистем и их связи;
- влияние через изменения режима хозяйственной деятельности, связанные с условиями радиоактивного загрязнения.

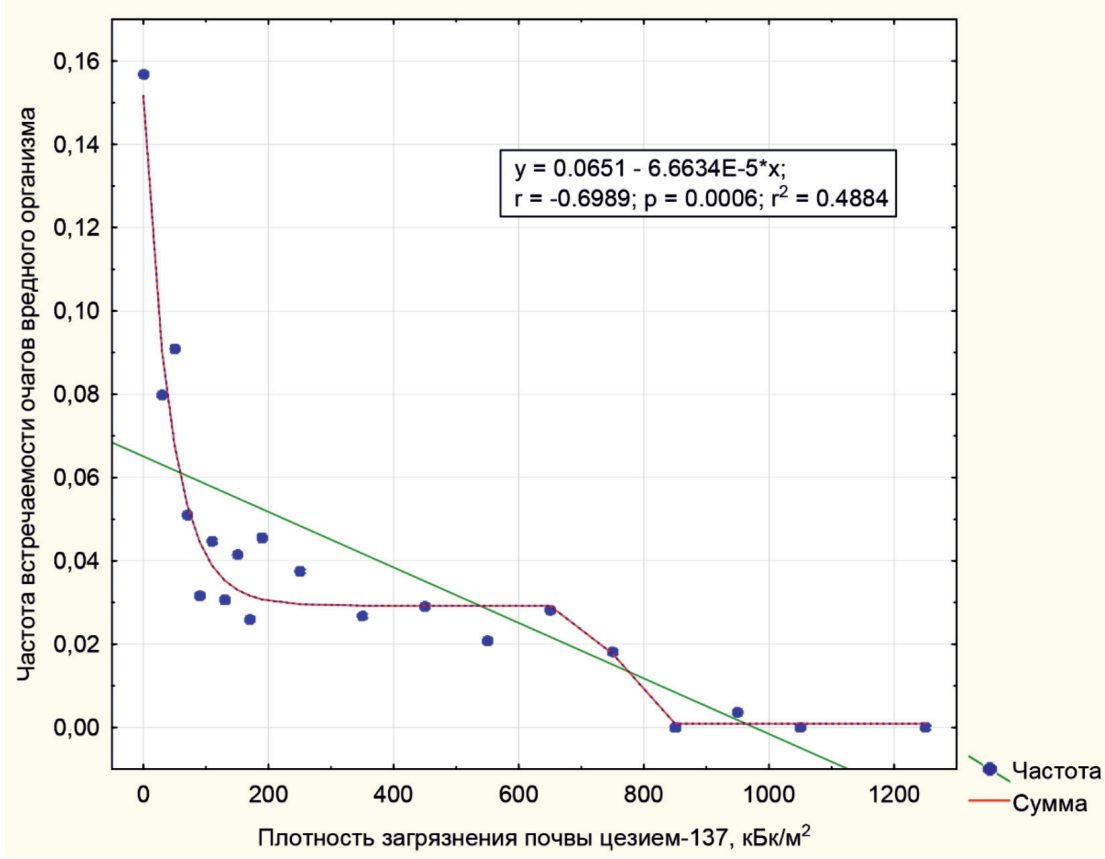

$A$

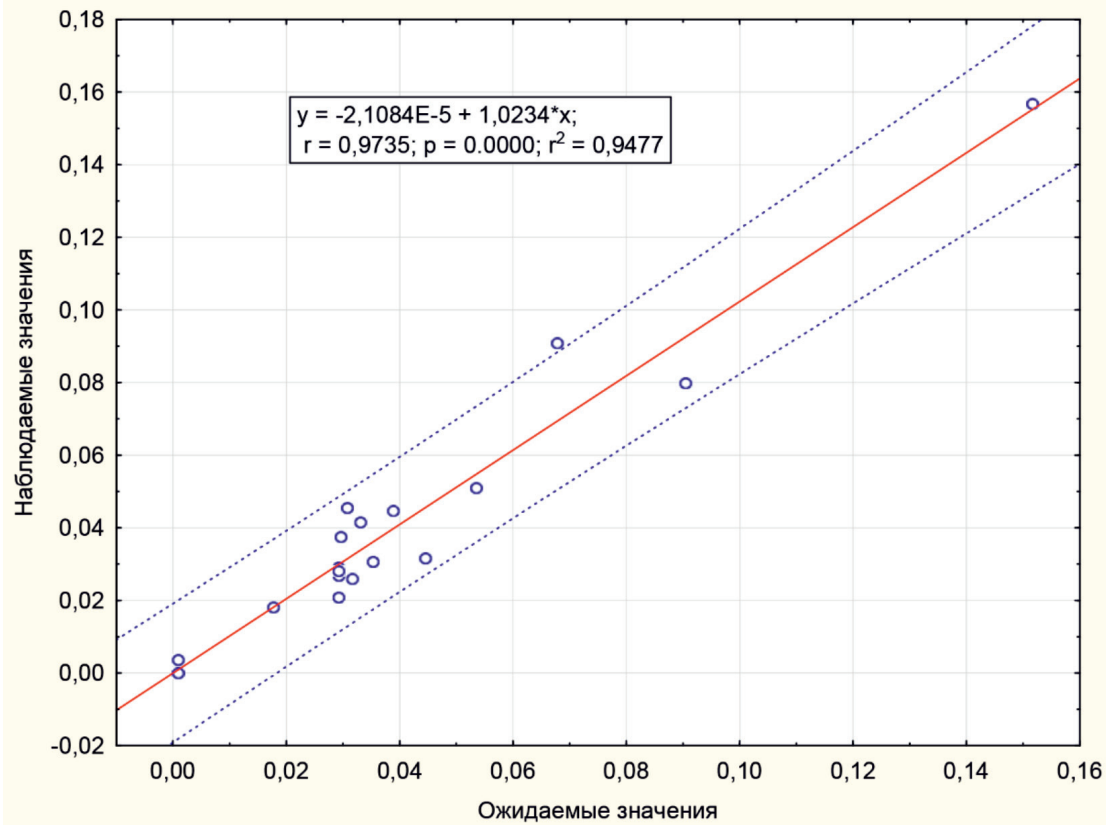

Б

Рис. 1. Распределение частот встречаемости очагов смоляного рака сосны (Peridermium pini (Willd.) Kleb.) в зависимости от плотности радиоактивного загрязнения почвы: A-Кривая двухкомпонентной зависимости доза - эффект; Б - Корреляция между ожидаемой (расчетной) и фактической вероятностью 


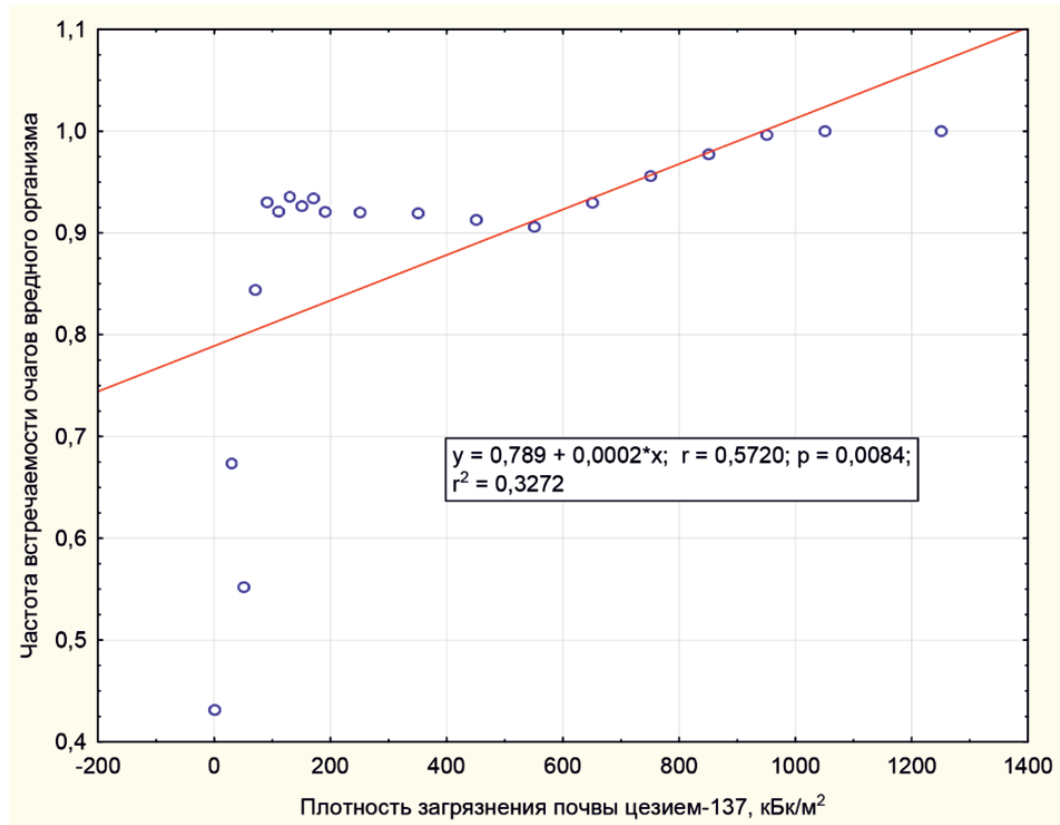

Puс. 2. Зависимость формирования очагов корневой губки (Heterobasidion annosum Fr.) на территории Брянской области от плотности загрязнения почвы ичезием-137

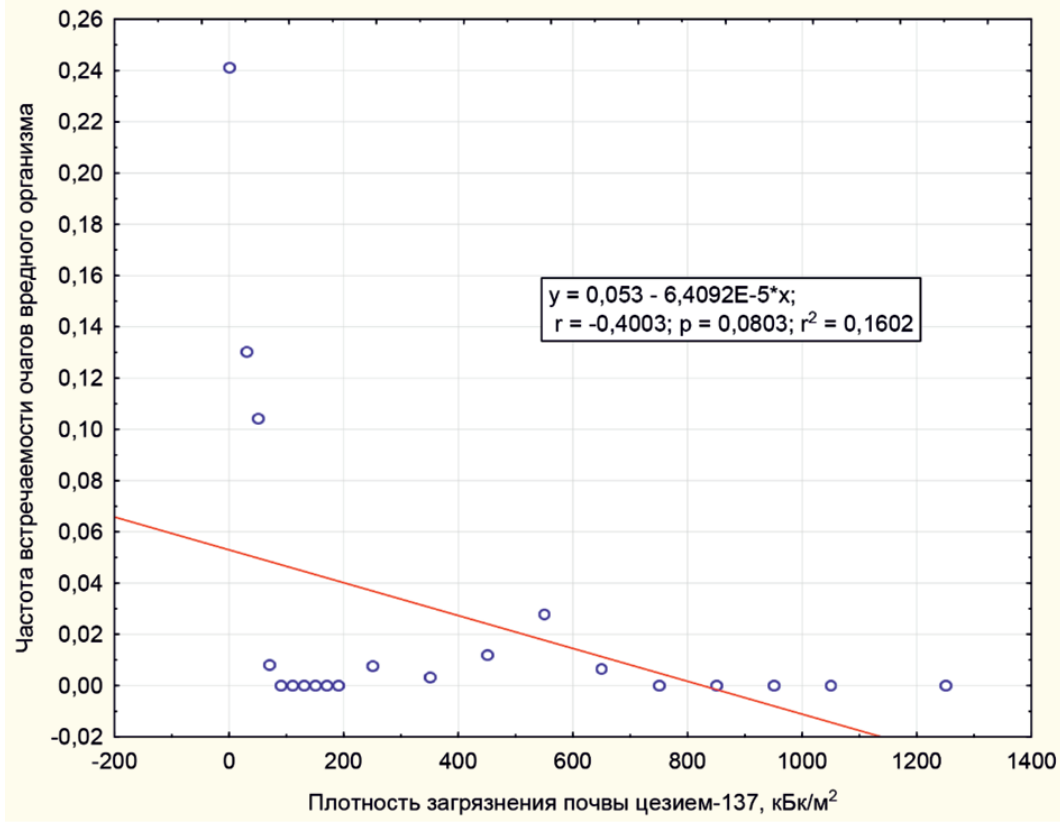

Pис. 3. Зависимость формирования очагов рыжего соснового пилильщика (Neodiprion sertifer Geoffr) на территории Брянской области от плотности загрязнения почвы цеезием-137

Таким образом, влияние радиоактивного загрязнения должно учитываться при осуществлении лесохозяйственной деятельности в загрязненных лесах, в том числе при лесопатологических обследованиях и осуществлении санитарно-оздоровительных мероприятий.

\section{Выводы}

Предложенный методический подход основывается на большом количестве (десятки тысяч) данных многолетних наблюдений, осуществляемых в ходе лесопатологических и радиационных обследований лесов. Он по- 
зволяет оценить влияние и значимость радиационного и других факторов на возникновение очагов патогенных организмов.

Полученные результаты позволяют установить наличие связей между плотностью загрязнения цезием-137 почв лесных участков и развитием патогенных организмов. Выявленные связи с большой вероятностью (95\%) могут рассматриваться как реально существующий факт (уровень р-значимости менее $5 \%(0,05))$. Исследуемая выборка хорошо отражает генеральную совокупность, и обнаруженные связи не могут быть подвергнуты сомнению.

Полученные результаты позволяют поновому взглянуть на взаимодействие живых организмов лесных экосистем между собой и с окружающей средой в условиях техногенного радиоактивного загрязнения (долговременного хронического облучения). Они позволяют выделить новое направление лесной радиоэкологии, изучающее влияние радиоактивного загрязнения и ионизирующих излучений на санитарное состояние лесных экосистем и развитие очагов патогенных организмов - радиационную лесопатологию Дальнейшее углубленное исследование влияния радиоактивного загрязнения на основные хозяйственно значимые виды вредителей и болезней необходимо для повышения эффективности защитных мероприятий и предотвращения негативных тенденций трансформации лесных экосистем.

\section{Список литературы / References}

1. INES. The international nuclear and radiological event scale. IATA 2008 Edition. Vienna, 2013. [Electronic resource] URL: https://www-pub.iaea.org/MTCD/Publications/PDF/INES2013web.pdf (date of access: 01.08.2019).

2. Проблемы ядерного наследия и пути их решения Вывод из эксплуатации / Под общ. ред. Л.А. Большова, Н.П. Лаверова, И.И. Линге. Т. 3. М., 2015. 316 с.

Nuclear legacy problems and solutions. Removal from operation / Pod obshchey redaktsiey L.A. Bol'shova, N.P. Laverova, I.I. Linge. T. 3. M., 2015. 316 p. (in Russian).

3. Криволуцкий Д.А., Тихомиров Ф.А., Фёдоров Е.А., Покаржевский А.Д., Таскаев А.И. Действие ионизирующей радиации на биогеоценоз. М.: Наука, 1988. 240 с.

Krivolutskiy D.A., Tikhomirov F.A., Fedorov E.A., Pokarzhevskiy A.D., Taskaev A.I. The effect of ionizing radiation on biogeocenosis. M.: Nauka, 1988. 240 p. (in Russian).

4. Панфилов А.В. Майские хрущи и сопутствующие вредители корней в условиях радиоактивного загрязнения: автореф. дис. .... канд. биол. наук. Москва, 1998. 24 с.
Panfilov A.V. Cockchafers and concomitant root pests in conditions of radioactive contamination: avtoref. dis. ... kand. biol. nauk. Moskva, 1998. 24 p. (in Russian).

5. Жуков А.М. Динамика лесопатологического состояния древостоев на загрязненных радионуклидами территориях // В книге: Вопросы лесной радиоэкологии / Под ред. А.И. Чилимова. М., 2000. С. 137-169.

Zhukov A.M. Dynamics of the forest pathological state of forest stands in territories contaminated with radionuclides // V knige: Voprosy lesnoy radioekologii / Pod red. A.I. Chilimova. M., 2000. P. 137-169 (in Russian).

6. Вайсерман А.М., Кошель Н.М., Мехова Л.В., Войтенко В.П. Радиационный гормезис в экспериментальных исследованиях // Медицинская радиология и радиационная безопасность. 2011. Т. 56. № 4. С. 5-16.

Vaiserman A.M., Koshel N.M., Mechova L.V., Voitenko V.P. Radiation Hormesis in Experimental Studies // Medical Radiology and Radiation Safety. 2011.V. 56. № 4. P. 5-16 (in Russian)

7. Раздайводин А.Н., Радин А.И., Калнин В.В., Павлов А.Н., Рябинков А.П., Карпов А.Д., Пророков А.А. Влияние ионизирующего излучения на развитие патогенных грибов рода Alternaria на семенах ясеня обыкновенного (Fraxinus excelsior L.) // Радиационные технологии в сельском хозяйстве и пищевой промышленности: состояние и перспективы: сборник докладов международной научно-практической конференции (Обнинск, 26-28 сентября 2018 г.). Обнинск: ФГБНУ ВНИИРАЭ, 2018. С. 114-117.

Razdayvodin A.N., Radin A.I., Kalnin V.V., Pavlov A.N., Ryabinkov A.P., Karpov A.D., Prorokov A.A. Influence of ionizing radiation on the development of pathogenic mushrooms of the genus Alternaria on seeds of Fraxinus excelsior L. // Radiatsionnye tekhnologii v sel'skom khozyaystve i pishchevoy promyshlennosti: sostoyanie i perspektivy: sbornik dokladov mezhdunarodnoy nauchno-prakticheskoy konferentsii (Obninsk, 26-28 sentyabrya 2018 g.). Obninsk: FGBNU VNIIRAE, 2018. P. 114-117 (in Russian).

8. ГОСТ Р 57973-2017 Санитарная безопасность в лесах. Термины и определения. Применяется c 01.06.2018. [Электронный ресурс]. URL: http://docs.cntd.ru/ document/1200157752 (дата обращения: 02.08.2019).

9. Приказ Министерства природных ресурсов и экологии РФ от 16.09.2016 № 480 «Об утверждении порядка проведения лесопатологических обследований и формы акта лесопатологического обследования» (с изменениями на 22 августа 2017 года). [Электронный ресурс] URL: https://base. garant.ru/71586766/ (дата обращения: 02.08.2019).

The order of the Ministry of Natural Resources and Environmental Protection of the Russian Federation from 09/16/2016 of No. 480 «On approval of the procedure for conducting forest pathological surveys and the form of the act of forest pathological survey» (as amended on August 22, 2017). [Electronic resource]. URL: https://base.garant. ru/71586766/ (date of access: 02.08.2019) (in Russian).

10. Ромашкин Д.Ю., Ромашкина И.В., Калнин В.В., Пророков А.А., Карпов А.Д. Морфогенетическая оценка биологической устойчивости лесных насаждений в условиях радиоактивного загрязнения // Лесной вестник. Forestry Bulletin. 2019. T. 23. № 2. C. 84-91. DOI: 10.18698/25421468-2019-2-84-91.

Romashkin D.Yu., Romashkina I.V., Kalnin V.V., Prorokov A.A., Karpov A.D. Morphogenetic evaluation of biological tolerance of forest stands under the conditions of radioactive contamination // Forestry Bulletin. 2019. V. 23. № 2. P. 84-91 (in Russian). 